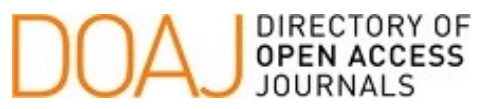

P-ISSN: 2548-5962

E-ISSN: 2548-981X

https://ojs.unud.ac.id/index.php/jbn

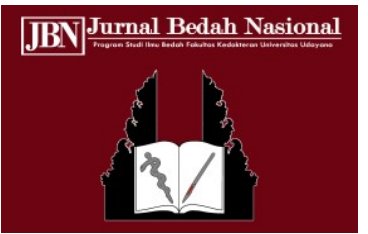

\section{Ruptur Ganda Tendon akibat Tebasan Senjata Samurai dengan Teknik Jahitan Rangkaian Bunga Melati: Sebuah Laporan Kasus dan Temuan Teknik Jahitan Baru}

\author{
Sophan Yahya Warnasouda ${ }^{1}$ \\ 1. Fakultas Kedokteran, Universitas Pasundan, Bandung. \\ Penulis korespondensi: sophanwarnasouda@yahoo.com.
}

\title{
ABSTRAK
}

Latar belakang: Ruptur tendon akibat kejahatan senjata tajam laras panjang (samurai) dapat mengakibatkan putusnya tendon berlapis-lapis, sehingga satu tendon dapat terbagi-bagi dan sulit untuk disatukan kembali. Oleh karena itu, maka diperlukan suatu teknik bedah baru yang cepat dan akurat. Kasus: Seorang pria berusia 30 tahun datang ke rumah sakit dengan luka bacok di lengan bawah kiri akibat kejahatan begal sepeda motor. Pemeriksaan fisik ditemukan beberapa luka di lengan bawah kiri, dekat pergelangan tangan. range of movement sendi pergelangan tangan kiri tidak dapat ekstensi. Pemeriksan radiologi ditemukan fraktur pada distal Ulna sinistra. Pasien ini didiagnosa dengan opened ruptur tendon ekstensor carpi ulnaris sinistra dan opened fraktur distal ulna sinistra, kemudian dilakukan open reduction and internal fixation with wiring, sedangkan multiple ruptur tendonnya di repair dengan suatu teknik bedah baru. Teknik repair tendon baru ini disebut dengan teknik operasi rangkaian bunga melati (chain of jasmine method) pada tahap awalnya, yang dilanjutkan dengan tindakan repair tendon klasik biasa. Evaluasi satu bulan setelah operasi menunjukkan tidak ada infeksi setelah operasi dan gerakan pergelangan tangan cukup baik, serta pasien merasa puas. Simpulan: Operasi reparasi tendon dengan teknik operasi rangkaian bunga melati ini dapat mempersingkat waktu operasi dan risiko kehilangan potongan tendon yang kecil serta tidak berantakan. Hasil operasi cukup baik, tidak ada infeksi setelah operasi dan pasien merasa puas.

Kata kunci: repair tendon, teknik operasi, metode rangkaian bunga melati.

DOI: https://doi.org/10.24843/JBN.2020.v04.i02.p05

\begin{abstract}
Background: Tendon rupture due to the crime of long sharp weapons (samurai) can result in the breaking of a multi-layered tendon, so that one tendon can be divided and difficult to put together again. Therefore, we need a new surgical technique that is fast and accurate. Case: A 30-year-old man came to the hospital with a slash on the left forearm due to a motorcycle crime. Physical examination found several injuries to the left forearm, near the wrist. The range of movement of the left wrist joint cannot be extended. Radiological examination found a fracture in the left distal ulna. This patient was diagnosed with opened tendon rupture of left extensor carpi ulnaris and opened fracture of left distal ulna, then performed open reduction and internal fixation with wiring, whereas multiple tendon ruptures are repaired with a new surgical technique. This new tendon repair technique is called the chain of jasmine method in the initial stage, followed by the usual classic tendon repair procedure. Evaluation one month after surgery showed no infection after surgery and wrist movements were quite good, and the patient was satisfied. Conclusion: Tendon repair operations with chain of jasmine method can shorten the operating time and risk of losing small pieces of tendon that are not cluttered. The results of the surgery are quite good, there is no infection after surgery and the patient feels satisfied.
\end{abstract}

Keywords: tendon repair, suturing technique, chain of jasmine method. 


\section{PENDAHULUAN}

Ruptur tendon merupakan jejas akut terhadap tendon akibat faktor dominan eksternal meskipun ada juga kontribusi faktor internal walaupun lebih kecil. ${ }^{1}$ Ruptur tendon umumnya dapat disebabkan oleh benda tajam seperti pisau dapur, kaca dan lain-lain. Keadaan ruptur tendon biasanya terbatas pada satu tingkat dalam satu tendon.

Ruptur tendon akibat senjata tajam laras panjang seperti samurai terjadi dalam kasus kejahatan begal. Keadaan yang ditemukan berupa ruptur berganda dalam satu tendon, sehingga dalam satu tendon terputus menjadi beberapa bagian kecil tendon. Bagian-bagian tendon yang putus ini mempunyai risiko terpisah dan dapat hilang. Oleh karena itu, dibutuhkan suatu teknik bedah untuk bagianbagian tendon yang terputus tersebut, agar tidak terpisah dan hilang.

Survei dari World Health Organization (WHO) tahun $2010,{ }^{2}$ menunjukkan kejadian infeksi daerah operasi meningkat 1,2 kasus per 100 prosedur bedah menjadi 23,6 kasus per 100 prosedur bedah. ${ }^{2}$ Untuk menurunkan angka kejadian infeksi setelah operasi memerlukan teknik operasi yang lebih cepat dan akurat. Waktu yang lebih cepat, berarti lama operasinya tidak terlalu lama; sedangkan akurat berarti tidak ada hal-hal yang terlupakan pada suatu prosedur operasi. Sepanjang penelusuran penulis di internet, ternyata belum ada teknik bedah untuk mencegah supaya potongan-potongan tendon yang terputus tersebut tidak berserakan dan hilang.

\section{LAPORAN KASUS}

Seorang pemuda berusia 30 tahun, datang ke rumah sakit dengan beberapa luka bacokan di lengan bawah kirinya oleh begal yang ingin merampas sepeda motornya. Saat kejadian, ketika begal membacok dengan samurai, pasien menangkis dengan lengan kirinya, sehingga terdapat luka tersebut.

Pemeriksaan fisik ditemukan beberapa luka benda tajam di lengan bawah kirinya yang berbatasan dengan pergelangan tangan. Pemeriksaan gerakan atau range of movement pergelangan kiri didapatkan tidak dapat melakukan ekstensi (Gambar 1). Pemeriksaan radiologi (rontgen pergelangan tangan kiri) didapatkan gambaran fraktur distal ulna sinistra (Gambar 2).

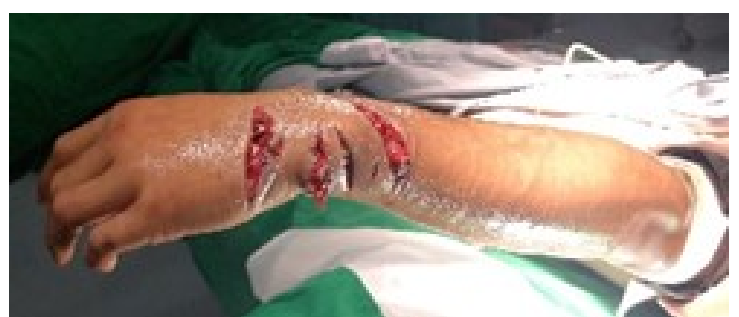

Gambar 1. Luka Benda Tajam pada Pergelangan Tangan Kiri.

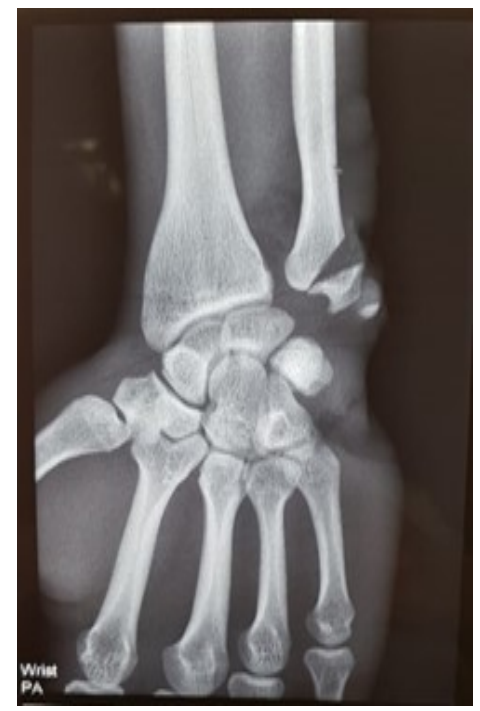

Gambar 2. Hasil Pemeriksaan Rontgen, tampak Fraktur Distal Ulna Sinistra.

Pelaksanaan operasi dilakukan sebagai berikut.

1. Dilakukan pemasangan tourniquet pada lengan atas kiri.

2. Melakukan prosedur asepsis di daerah operasi, lalu pencucian dan membuang jaringan yang mati (debridement). 
3. Penatalaksanaan fraktur distal Ulna yaitu sebelum melakukan tindakan repair tendon, dilakukan reposisi, lalu fiksasi dengan $K$-wire (Gambar 3).

4. Penatalaksanaan ruptur tendon (tendon suturing techniques), yaitu tendon yang terpotong-potong oleh benda tajam, terpisah satu dengan yang lainnya tersebut didekatkan dan dipertahankan dengan jahitan benang dan merangkainya seperti bunga melati pengantin terlebih dahulu (chain of jasmine method). Setelah itu, direparasi tendon dengan "teknik klasik". Teknik penjahitan tendon (tendon repair) memakai cara Bunnell dan modifikasinya, karena ahli bedah sudah familiar dan hasil kekuatannya cukup kuat (Gambar 4, 5, dan 6). ${ }^{3}$

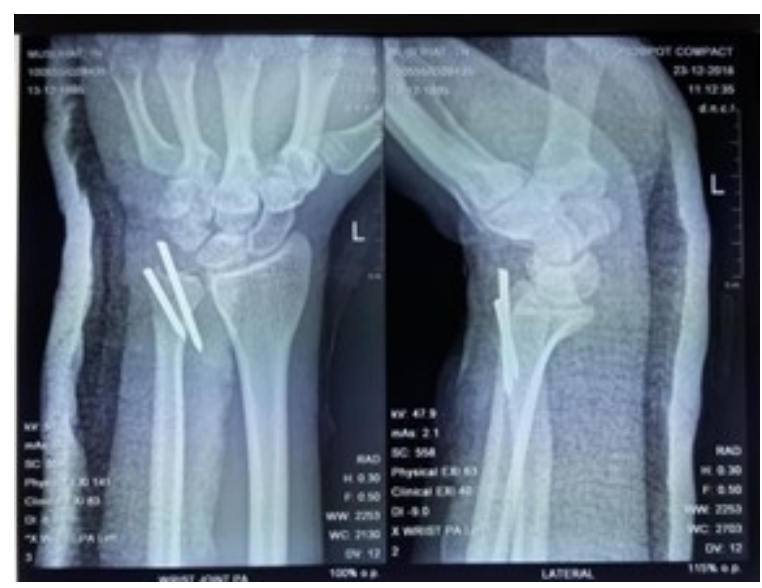

Gambar 3. Hasil Pemeriksaan Rontgen, Setelah Operasi ORIF Distal Ulna.

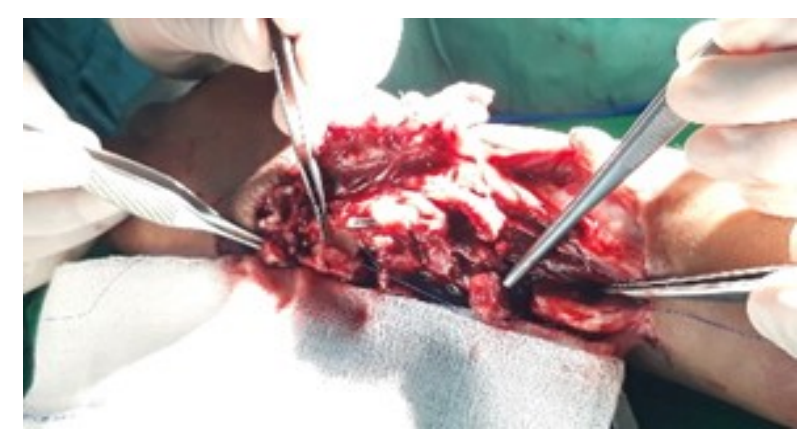

Gambar 4. Suturing Techniques dengan Chain of Jasmine Method.

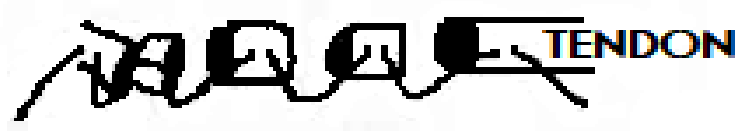

Gambar 5. Skematis Teknik Tendon Repair "Rangkaian Bunga Melati".

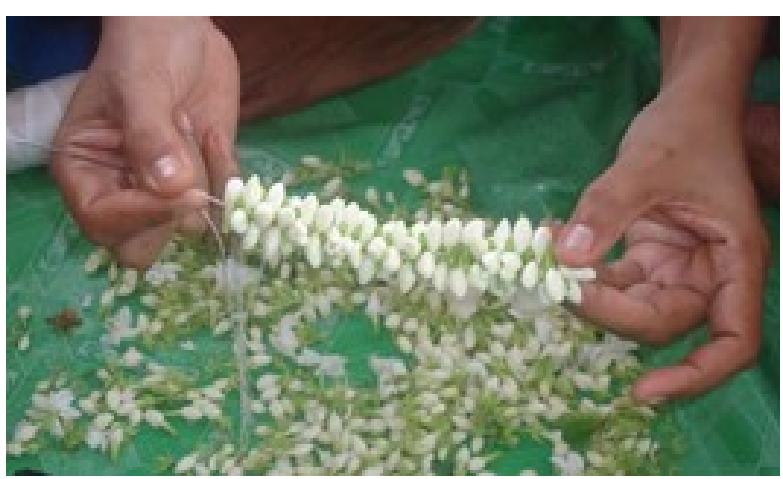

Gambar 6. Rangkaian Bunga Melati.

Berdasarkan teknik ini, potonganpotongan tendon akan lebih mudah disambung kembali dan tidak ada yang hilang dari lapangan operasi.

Keuntungan dengan teknik bedah rangkaian bunga melati ini akan mempercepat waktu operasi, terhindar dari kehilangan potongan tendon yang kecil dan berantakan, sehingga operasinya bisa lebih cepat dan akurat.

Setelah selesai penanganan fraktur distal ulna dan reparasi tendon memakan waktu kurang lebih sekitar 1,5 jam, lalu dipasang back slab dengan posisi pergelangan tangan ekstensi.

Semua tindakan operasi ini dilakukan oleh satu orang dokter bedah ortopedi dan dibantu oleh dua orang perawat bedah.

\section{Follow-up setelah operasi}

Satu bulan setelah operasi didapatkan hasil sebagai berikut.

1. Tidak ada infeksi setelah operasi.

2. Pergerakan pergelangan tangan kurang lebih 75 derajat ekstensi, 15 derajat fleksi; tetapi pasien merasa puas atas hasil operasi (Gambar 7 dan 8). 


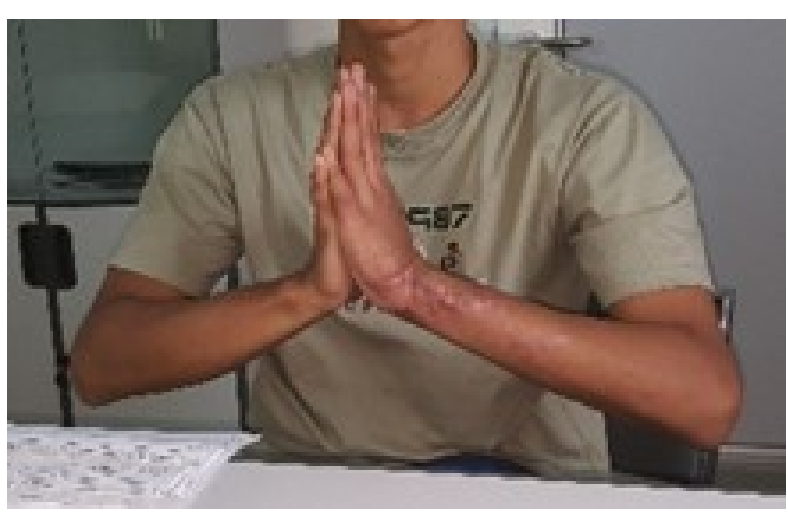

Gambar 7. Menunjukkan Ekstensi Pergelangan.Tangan Kiri.

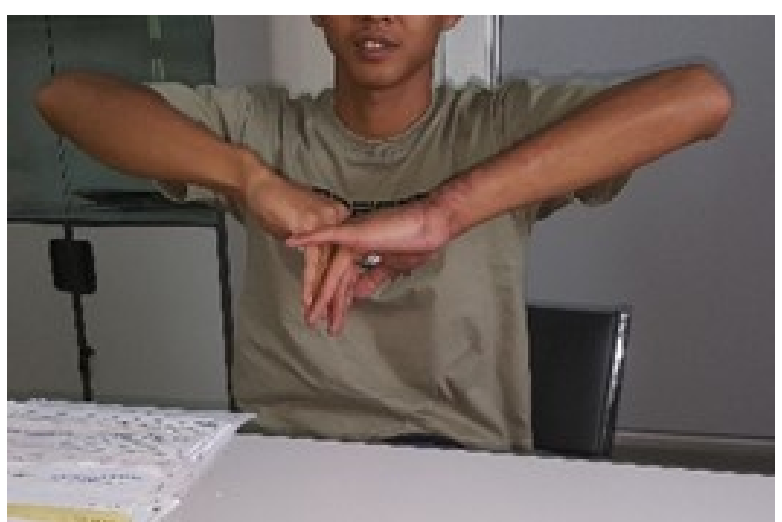

Gambar 8. Fleksi dari Pergelangan Tangan Kiri.

\section{DISKUSI}

Seperti yang disimpulkan oleh survei WHO tahun 2010, ${ }^{2}$ menunjukkan kejadian infeksi daerah operasi meningkat pada prosedur bedah, sehingga dibutuhkan teknik operasi yang lebih cepat, dan akurat pada umumnya serta pada operasi repair tendon khususnya.

Penanganan ruptur tendon, misalnya tendon otot flexor (juga extensor) terus berkembang dari waktu ke waktu. Perbaikan dan modifikasi serta penyempurnaan atas teknik-teknik lama yang sudah baku terus dilakukan dalam upaya mendapatkan hasil yang maksimal dalam penyembuhan. ${ }^{4}$

Penyambungan tendon yang baik akan dapat mengembalikan kontinuitas tendon tanpa menimbulkan adhesi/perlekatan atau bentuk sambungan yang menghalangi gliding. Penanganan cedera tendon yang tidak optimal dapat menyebabkan adhesi dan gangguan fungsi bahkan dapat terjadi ruptur/putus ulang. ${ }^{5}$

Terjadinya celah sambungan (gap formation) dan ruptur ulang pada sambungan adalah tanda terjadinya kelemahan penanganan cedera tendon. ${ }^{6}$ Hal tersebut memperlihatkan kelemahan fungsi dari jahitan, teknik dan biomekanik tendon pada saat-saat awal setelah perbaikan. ${ }^{4}$ Peningkatan celah sambungan memberikan hasil klinis yang buruk. Oleh sebab itu, salah satu target penyambungan tendon adalah memperbaiki atau mempertahankan fungsi gliding. $^{7}$

Menurut Kangas, ${ }^{8}$ faktor-faktor yang mempengaruhi penyembuhan tendon secara garis besar dibagi menjadi faktor-faktor intrinsik dan ekstrinsik. Faktor intrinsik yaitu faktor yang mempengaruhi oleh keadaan pasien sendiri, antara lain terdiri atas faktor gizi, usia, ambang rasa nyeri dan motivasi dari pasien. Sedangkan, pada faktor ekstrinsik, antara lain terdiri atas jenis luka, lokasi atau tingkat ruptur tendon, limit waktu antara kejadian, dan pertolongan serta teknik penanganan ruptur tendon yang baik.

Dominasi laporan penanganan kasus ruptur tendon bertujuan untuk mengetahui tentang perbandingan kekuatan jahitan antara teknik jahitan tertentu. ${ }^{9}$ Contoh pada teknik cross stitch dibandingkan dengan teknik jahitan Kessler, terdapat modifikasi dalam terapi bedah terhadap lesi tendon atau penanganan rehabilitasi setelah operasi repair tendon.

Kasus ruptur tendon bertingkat ganda atau akibat bacokan senjata tajam berkali-kali pada satu tendon sangat jarang terjadi. Salah satu faktor kemungkinan adanya cidera berganda adalah adanya kasus kejahatan dengan senjata tajam laras panjang yang tinggi seperti samurai. Walaupun mungkin ada kejadiannya, namun belum tentu teknik operasi repair tendon dilaporkan atau ditulis 
dalam jurnal. Sepanjang penelusuran peneliti di internet, peneliti belum menemukan adanya penulisan dengan teknik operasi yang sama. Oleh karena itu, teknik operasi repair tendon ini tidak dapat dibandingkan dengan teknik operasi repair tendon oleh penulis lain.

Berdasarkan laporan kasus ini, telah ditemukan suatu teknik operasi untuk mencegah terjadinya gap formation pada khususnya dan cara mencegah kehilangan bagian-bagian tendon yang terputus pada umumnya. Secara berurutan teknik operasi ini yaitu dengan cara merangkaikan terlebih dahulu seperti rangkaian bunga melati, kemudian baru direparasi atau disambungkan tendonnya dengan teknik jahitan seperti biasanya. Dengan sudah ditentukannya terlebih dahulu secara merangkaikan potongan-potongan tendon yang terputus, maka tidak ada waktu untuk merasa kebingungan antara menjahit dan mencaricari potongan tendon yang berserakan. Hal tersebut dapat disebabkan oleh lengkapnya komponen tendon yang terputus dan teknik jahitan yang rapi, maka hasil reparasi tendonnya akan terhindar dari adanya gap formation yang mungkin terjadi. Dengan tidak adanya gap formation, maka akan terhindar pula salah satu penyebab risiko infeksi setelah operasi. Oleh karena hal-hal yang telah diuraikan tersebut di atas, dengan manajemen efektif dan efisien, maka teknik operasi repair tendon cara rangkaian melati ini akan berjalan relatif lebih cepat.

Keuntungan dari teknik repair tendon ini, yaitu: 1) terhindar dari kehilangan bagianbagian tendon yang terpotong; 2) mencegah adanya gap formation; 3) mengurangi risiko infeksi setelah operasi; dan 4) waktu operasi relatif lebih cepat.

\section{SIMPULAN}

Operasi reparasi tendon dengan teknik operasi rangkaian bunga melati (Suturing Techniques with Chain of Jasmine Method) ini dapat mempersingkat waktu operasi dan risiko kehilangan potongan tendon yang kecil serta tidak berantakan. Hasil operasi cukup baik, tidak ada infeksi setelah operasi dan pasien merasa puas.

\section{PERNYATAAN}

Penulis menyatakan tidak terdapat konflik kepentingan dalam penulisan artikel ini.

\section{DAFTAR PUSTAKA}

1. Griffin M, Hindocha S, Jordan D, dkk. An Overview of the management of flexor tendon injuries. Open Orthop $J$. 2012;6:28-35.

2. World Health Organization. The burden of health care-associated infection worldwide: a summary. World Health Organization [serial online] 2010 [diakses 9 Januari 2020]. Diunduh dari: https://www.who.int/gpsc/country_work/ summary_20100430_en.pdf.

3. Rawson S, Cartmell S, Wong J. Suture techniques for tendon repair; a comparative review. Muscles Ligaments Tendons J. 2013;3:220-8.

4. Maquirriain J. Achilles tendon rupture: avoiding tendon lengthening during surgical repair and rehabilitation. Yale $J$ Biol Med. 2011;84:289-300.

5. Khanna A, Friel M, Gougoulias N, dkk. Prevention of adhesions in surgery of the flexor tendons of the hand: what is the evidence? Br Med Bull. 2009;90:85-109.

6. Killian ML, Cavinatto L, Shah SA, dkk. The effects of chronic unloading and gap formation on tendon-to-bone healing in a rat model of massive rotator cuff tears. $J$ Orthop Res. 2014;32:439-47. 
7. Eliasson P. Response to mechanical loading in healing tendons [disertasi]. Linköping: Linköping University; 2011.

9. Pohan ESD, Pohan DJ. Ruptur Tendon dan Penanganannya: Perbandingan Kekuatan Jahitan Teknik Cross Stitch

8. Kangas J. Outcome of total Achilles Dan Teknik Kessler Modifikasi. Jurnal tendon rupture repair, with special reference to suture materials and postoperative treatment [disertasi]. Oulu: University of Oulu; 2007. 